\title{
Molecular markers of susceptibility to ocular toxoplasmosis, host and guest behaving badly
}

\author{
Adriana Lima Vallochi' \\ Anna Carla Goldberg ${ }^{2}$ \\ Angela Falcai ${ }^{3}$ \\ Rajendranath Ramasawmy ${ }^{4}$ \\ Jorge Kalil ${ }^{4}$ \\ Cláudio Silveira ${ }^{5}$ \\ Rubens Belfort Jr ${ }^{5}$ \\ Luiz Vicente Rizzo ${ }^{3}$ \\ 'Oswaldo Cruz Institution (IOC), \\ Oswaldo Cruz Foundation \\ (FIOCRUZ), Rio de Janeiro, RJ, Brazil; \\ ${ }^{2}$ NUCEL - Cellular and Molecular \\ Therapy Center, University of \\ São Paulo, São Paulo, SP, Brazil; \\ ${ }^{3}$ Department of Immunology, \\ Biomedical Science Institute, \\ University of São Paulo, São Paulo, \\ SP, Brazil; ${ }^{4}$ Laboratory of Immunology, \\ Heart Institute, University \\ of São Paulo Medical School, \\ São Paulo, SP, Brazil; ${ }^{5}$ Department \\ of Ophthalmology, Federal University \\ of São Paulo, São Paulo, SP, Brazil
}

Correspondence: Adriana Lima Vallochi IOC-FIOCRUZ, Av. Brasil, 4365,

Manguinhos, 21 040-900, Rio de Janeiro,

RJ, Brazil

Tel +552138658161

$\mathrm{Fax}+552125903495$

Email vallochi@ioc.fiocruz.br

\begin{abstract}
Infection with Toxoplasma gondii results in retinochoroiditis in $6 \%$ to $20 \%$ of immunocompetent individuals. The outcome of infection is the result of a set of interactions involving host genetic background, environmental, and social factors, and the genetic background of the parasite, all of which can be further modified by additional infections or even reinfection. Genes that encode several components of the immune system exhibit polymorphisms in their regulatory and coding regions that affect level and type of expression in response to stimuli, directing the immune response into different pathways. These variant alleles have been associated with susceptibility to immune-mediated diseases and with severity of pathology. We have investigated polymorphisms in several of these genes, identified as candidates for progression to retinochoroiditis caused by toxoplasmosis, namely chemokine (C-C motif) receptor 5 (CCR5), toll-like receptor-2 (TLR2), and TLR4. Furthermore, because interleukin-12 (IL-12) has been shown to be fundamental both in mice and in man to control a protective response against T. gondii, molecules that have a key function in IL-12 production will be emphasized in this review, in addition to discussing the importance of the genetic background of the parasite in the establishment of ocular disease.
\end{abstract}

Keywords: ocular toxoplasmosis, IL-12, TLR, CCR5, immunity

Toxoplasma gondii, an obligate intracellular protozoan parasite, infects close to a billion people worldwide (Tenter et al 2000) and is an important agent of animal and human disease worldwide (Dubey and Beattie 1988; Wong and Remington 1993; Petersen and Dubey 2001).

Toxoplasmosis in humans and other mammals is acquired by oral ingestion of either tissue cysts in raw or undercooked meat from chronically infected intermediate hosts or by ingestion of oocysts shed by cats by way of fecal contamination of food or water (Frenkel 1988, 1990). Once ingested, the cyst wall is digested within the lumen of the small intestine. The acute phase of infection is characterized by wide-spread dissemination of rapidly dividing tachyzoites that invade virtually all cell types.

During the inflammatory process, soluble mediators and cellular components work together in a systematic manner in the attempt to contain and to eliminate the agents causing physical distress. The nature and portal of entry of the foreign substance and, to some degree, the nature and circumstances of a particular individual influence the way in which the inflammatory process is initiated.

Pathogens can initiate inflammation by a number of distinct and characteristic mechanisms, including activation of the plasma protease systems by interaction with degradation products of the pathogens and by secretion of toxins that can activate the inflammatory response directly. Injured cells themselves can release degradation products that initiate one or more of the plasma protease cascades and augment expression of proinflammatory cytokines that promote the inflammatory 
process. The physiological changes in inflammation are crucial to maintain the health and integrity of an organism, however, the inflammatory process can result in massive tissue destruction when poorly controlled.

During invasion of $T$. gondii, the host cell is essentially passive and no change is detected in membrane ruffling, actin cytoskeleton, or phosphorylation of host cell proteins (Furtado et al 1992; Manger et al 1998; Ortega-Barria and Boothroyd 1999; Jacquet et al 2001). The invasion is an active parasite-mediated process, initiated by contact between the apex of $T$. gondii and the host cell surface, involving many host receptors (proteoglycans like heparin and heparin-sulphate, $\beta$-integrins) and parasite ligands such as surface antigens (SAG), surface antigen-related sequences (SRS), microneme proteins (MIC), and laminin (Yap and Sher 1999).

Intestinal epithelial cells probably are the first cells infected by $T$. gondii. Chemokines released by these cells play a critical role in the initiation and modulation of immune response to various pathogens (Perez de Lema et al 2001). They are responsible for the chemoattraction of polymorphonuclear neutrophils (PMNs), dendritic cells (DC), macrophages (MØ), and lymphocytes (Mackay 2001). T. gondii infects and can be disseminated by these cells to other organs throughout the host, especially to, muscle and central nervous system.

\section{The disease in animal models}

The $T$. gondii mouse infection model, because of its simplicity and robust responses it generates, has proven a powerful tool for studying host-microbe interactions. Because of that, most of the data published on immune responses and genes implicated in susceptibility derive from studies employing inbred mouse strains. Infection of mice leads to lifelong persistence of the parasite. Outcome is variable, depending on the interaction of many factors like inoculum size (Liesenfeld 1999), virulence of the organism ( $\mathrm{Su}$ et al 2002), life cycle stage of the parasite (Johnson 1984; McLeod et al 1989a; Suzuki et al 1989a, 1993), genetic background (Williams et al 1978; McLeod et al 1989b; Suzuki et al 1996; Lu et al 2005), gender (Roberts et al 1995), and immunological status. All these factors seem to affect the course of infection in human beings and in animal models of toxoplasmosis.

Murine susceptibility to T. gondii or resistance to mortality following acute oral infection is under multigenic control by the host (Williams et al 1978; McLeod et al 1989a; Johnson et al 2002). In C57BL/6 mice, genes both within and outside of the major histocompatibility complex (MHC) are involved in impaired intracerebral immune response (Brown and McLeod 1990; Deckert-Schluter et al 1994).

The ability of mice to survive $T$. gondii infection is dependent on strong T cell-mediated immunity. Both CD4+ T helper (Th) 1 cells and CD8+ cytolytic $\mathrm{T}$ lymphocytes are vital in providing protective immunity and long-term survival during chronic infection, as determined by in vivo depletion studies and adoptive transfer of CD4+ and CD8+ T cell lines and clones (Suzuki et al 1988; Gazzinelli et al 1991, 1992; Parker et al 1991; Kasper et al 1992; Buzoni-Gatel et al 1997). If the host becomes immunosuppressed, chronic infection can be reactivated, leading to toxoplasmic encephalitis, which is often fatal if not treated (Suzuki 2002).

The protective competence of these cell types is due to their ability to produce interferon (IFN)- $\gamma$, a pro-inflammatory cytokine that has become well known as the major mediator of resistance to T. gondii (Suzuki et al 1988). Mice that do not express IFN- $\gamma$ (IFN- $\gamma$ knockout mice) are unable to survive the acute phase of infection (Scharton-Kersten et al 1996). Antibody-mediated depletion of this cytokine during chronic infection demonstrates that continued IFN- $\gamma$ production is necessary for long-term survival (Gazzinelli et al 1992). However, pathologic consequences due to overproduction of cytokines and excessive activation of the immune system are observed in IL-10 knockout (IL-10 KO) mice infected with T. gondii (Gazzinelli et al 1996) or wild type mice infected with highly virulent strains (Mordue et al 2001).

The activation of murine macrophages (MØ) by IFN- $\gamma$ in the presence of additional signals, such as lipopolysaccharide (LPS) or tumor necrosis factor- $\alpha$ (TNF- $\alpha$ ), is necessary to trigger the cytotoxic activity of MØ against $T$. gondii (Sibley et al 1993). IFN- $\gamma$ exerts its antimicrobial activity through induction of specific effector molecules, including reactive nitrogen intermediates that interfere with key metabolic enzymes (Khan et al 1997; Scharton-Kersten et al 1997; Roberts et al 2000), indoleamine 2,3-dioxygenase (IDO) that induces tryptophan degradation thereby interfering with viability of the parasite (MacKenzie et al 1999; Fujigaki et al 2002; Silva et al 2002), and a family of GTP-binding proteins. IFN- $\gamma$-inducible GTP-binding proteins IGTP and LRP-47 are required for the mice to survive acute T. gondii infection, while nitric oxide-dependent protection may be more important during chronic infection (Taylor et al 2000; Collazo et al 2001).

The intraocular inflammatory response to the parasite is also mediated primarily by the $\mathrm{CD} 4{ }^{+} \mathrm{T}$ - and $\mathrm{CD} 8+\mathrm{T}$-cell responses. $\mathrm{CD}^{+} \mathrm{T}$ cells recognize and destroy parasiteinfected cells in an MHC class I restricted manner. However, 
as part of the local immune privilege, cells in the eye express low levels of MHC class I while infected mice usually show increased expression (Lyons et al 2001). This would, in turn, permit the precise targeting of T. gondii-infected cells by CD8+ cytolytic T lymphocytes and unlike other killing mechanisms that rely on soluble mediators, would limit collateral damage to uninfected cells. Indeed, depletion of the $\mathrm{CD} 8^{+}$cell subset resulted in increased lesion formation and cyst burden in an acquired disease model of infection (Gazzinelli et al 1994a), and a severe necrosis accompanied by higher ocular parasite burdens, in CD8-deficient mice immunized and challenged by a intraocular inoculum (Lu et al 2004). B cells may also contribute by limiting tachyzoite proliferation in the eyes (Lu et al 2004).

Programmed cell death is an important protective strategy used in immune-privileged organs. Fas is expressed on a variety of immune and nonimmune cells, whilst FasL is evident on $\mathrm{T}$ cells as well as in immune-privileged tissues. Ligation of these two surface molecules results in apoptosis of the Fas-expressing cell. In this way, the eye can prevent the damage caused by infiltrating lymphocytes and activated $\mathrm{T}$ cells can induce apoptosis in infected cells. T. gondii induces increased Fas and FasL expression on the cells of mouse retina. When intracamerally inoculated with tachyzoites of one virulent strain, Fas- and FasL-defective mice exhibit greater inflammatory scores and a more severe histopathology than similarly infected wild-type mice, added to a reduced ability to limit parasite proliferation early in infection (Hu et al 1999, 2001). However, when intraperitoneally inoculated with a less virulent strain, the same mice showed no difference in the degree of ocular inflammation and apoptosis. The higher level of IFN- $\gamma$ and NO apparent early in these mice must have provided an alternative means to control parasitemia in the absence of Fas or FasL expression (Shen et al 2001).

In the immunosuppressed environment of the eye with high levels of TGF- $\beta$ antigen-presenting cells can produce IL-10 when activated, which would stimulate the expansion of a regulatory $\mathrm{T}$ cell subset able to counteract the Th1 type pro-inflammatory responses and thus maintain the immune privilege. Nevertheless, the ocular pathogenesis in C57BL/6 mice is more severe than that of $\mathrm{BALB} / \mathrm{c}$ and $\mathrm{CBA} / \mathrm{J}$ mice and the serum levels of IFN- $\gamma$ and TNF- $\alpha$ in $\mathrm{C} 57 \mathrm{BL} / 6$ mice are significantly higher than those in BALB/c and CBA/J mice following ocular infection with a virulent strain of $T$. gondii (Lu et al 2005). There are higher levels of IFN- $\gamma$ mRNA expression in the retinas of C57BL/6 mice than in those of
BALB/c mice infected with T. gondii (Norose et al 2003). Furthermore, a decline in IFN- $\gamma$ production in CD4-KO mice protects mice from mortality due to an exacerbated immune response (Casciotti et al 2002). IFN- $\gamma$ has been shown to regulate the $T$. gondii load and inter-conversion between the bradyzoite and tachyzoite stages of $T$. gondii in the murine eye (Norose et al 2003). Therefore, IFN- $\gamma$ mediates immunopathology and contributes to early death following $T$. gondii infection (Liesenfeld et al 1996).

\section{Toxoplasmosis}

Some recent studies support the idea that $T$. gondii is a master manipulator of host immune responses. The parasite simultaneously triggers the secretion of protective cytokines (IFN- $\gamma$ and IL-12) and paradoxically suppresses the same type of response (Denkers et al 2004; Gaddi and Yap 2007). This dual capacity of the parasite could actually be beneficial and allow the establishment of a stable host-parasite interaction. Failure to successfully synchronize these responses has negative consequences for both. Antimicrobial protection is ensured by the coordinated action of the innate and adaptative immune systems. Molecular communication between the host innate immune system and the intracellular protozoan T. gondii is fast emerging as a dramatic example of these key principles in action.

In the immunocompetent host the acute infection is usually asymptomatic or causes a influenza-like syndrome, and rarely leads to severe symptoms such as interstitial pneumonia, pericardial effusions, myositis, myocarditis, and neurological disorders (retinochoroiditis, Guillain-Barré syndrome, mental confusion) (Bossi and Bricaire 2004). Encephalitis is most commonly seen in immunocompromised individuals whereas uveitis is the most common lesion appearing in immunocompetent individuals (Hill and Dubey 2002). The infection incites a quasiefficient immune response, which controls parasitemia but allows tissue cysts to form in the brain, eyes, and muscles, leading to lifelong persistence of the parasite and variable medical outcome.

Dissemination of $T$. gondii in immunocompromised hosts, such as AIDS patients with very low CD4 counts, patients under immunosuppression to prevent or treat transplant rejection, and fetuses, is common, and often represents a reactivation of an earlier infection, rather than a newly acquired one. In these individuals the parasite can, besides encephalitis and retinochoroiditis, cause carditis, pneumonia, and meningitis, amongst other manifestations (Hill and Dubey 2002; Mele et al 2002; Montoya and Liesenfeld 2004). 
Ocular lesions may result from congenital or after birth-acquired infections. The lesion is often necrotic, destroying the architecture of the neural retina and sometimes involving the choroid (retinochoroiditis). Typical findings of toxoplasmic retinochoroiditis include white focal lesions with an intense overlaying and vitreal inflammatory reaction. Toxoplasmic retinochoroiditis is the most common lesion caused by infection with this protozoan and it may occur either immediately or long after the initial infection (Silveira et al 1988; Couvreur and Thulliez 1996; Montoya and Remington 1996) or reactivation (Bosch-Driessen et al 2002).

Recurrent lesions are usually identified at the borders of the retinochoroidal scars, are typically found in clusters, and have been attributed to the rupture of tissue cysts within these old lesions or eventually coming from other tissues due to activation of memory immune cells. It is thought that the satellite lesions occurring both in the brain and the eye are caused by rupture of local cysts (Holland 2003, 2004), but the origin of active infections in remote tissues has been credited to either clinically unapparent tissue cysts or to re-infection (Hill and Dubey 2002). In this last case, it is conceivable that the immune response by memory cells might be triggered by circulating parasites or even by other infections, through the activation of IFN- $\gamma$ and other inflammatory mediators.

Many questions about the disease still remain that confound ophthalmologists (Vallochi et al 2002; Holland $2003,2004)$. The response to antibiotic therapy alone or in combination with corticosteroids varies widely among patients (Stanford et al 2003). Clinical presentation also varies, with some patients presenting only one episode of mild inflammation whereas others have multiple recurrences of severe uveitis leading to loss of eyesight. The immune response against retinal antigens does not explain the extensive damage to the eye in patients with ocular toxoplasmosis. Furthermore, we have presented data suggesting that a controlled autoimmune response may develop after infection with $T$. gondii in some patients and, in addition, may help to prevent the parasite from spreading through the retina thus associated with a milder disease (Vallochi et al 2005a).

Familial ocular toxoplasmosis is found in southern Brazil, where the incidence of ocular toxoplasmosis is higher than in most regions of the globe, and accounts for $70 \%$ to $90 \%$ of all uveitis cases seen in rural areas. A household survey in the endemic area showed $17,7 \%(186 / 1,042)$ of the population had toxoplasmic scars in the retina (Silveira et al 1988; Glasner et al 1992), a finding that cannot be explained by congenital infection alone (Holland 2003, 2004). The same population was reassessed 7 and 11 years later and showed that seroconversion was more frequent in individuals under 17 years of age or above 50 years of age, with a risk of $10 \%$ of ocular involvement (Silveira et al 2001; Silveira 2002). Finally, acquired infection causing late necrotizing retinochoroiditis is seen not only in Brazil (Nussenblatt and Belfort 1994), but also in Europe (Brezin and Cisneros 1999) and in the USA (Montoya and Remington 1996).

Analysis of systemic cellular response to T. gondii antigen in 136 subjects with a diagnosis of ocular toxoplasmosis, no ocular disease or no infection by $T$. gondii suggested that resistance to the development of ocular toxoplasmosis has been associated with the ability to mount a lasting T-helper (Th) 1-type response (IL-2 and IFN- $\gamma$ production) to the parasite antigens. On the other hand, susceptibility has also been associated with an inflammatory response, mostly mediated by cytokines (IL-1 and TNF- $\alpha$ ) possibly produced by activated macrophages (MØ), which may themselves take part in the pathological features of the disease (Yamamoto et al 2000).

A recent study performed in France is in opposition to our study. Analyzing the induction of CD25 expression, no significant difference was observed in immune response among 16 individuals with a diagnosis of congenital, acquired, or undetermined ocular toxoplasmosis or between patients with active or inactive ocular lesions. Furthermore, higher levels of IFN- $\gamma$ were detected in stimulated blood cultures from infected patients than in those from controls, with no difference between patients with asymptomatic or ocular toxoplasmosis (Fatoohi et al 2006).

TNF- $\alpha$ also plays an important role in murine resistance to acute and chronic toxoplasmosis (Chang et al 1990; Johnson 1992; Langermans et al 1992). However, high levels of this cytokine produced during any lethal infection can potentially contribute to harmful cerebral and hepatic effects (Black et al 1989; Beaman et al 1992; Marshall et al 1999). Furthermore, TNF- $\alpha$ may aid the intracerebral dissemination of $T$. gondii in mice (Grau et al 1992) and may be increased in toxoplasmic retinochoroidal in humans (Yamamoto et al 2000).

We have shown that individuals with ocular toxoplasmosis from congenital infection have a diminished immune response towards $T$. gondii antigens when compared with individuals with ocular disease due to acquired infection (Yamamoto et al 2000). Interestingly, unlike mice, the diminished response is not caused by a superantigen (Vallochi et al 2001). This means that, despite the similarity at macroscopic and histopathologic level, the lesions seen on 
ocular toxoplasmosis may be generated by different mechanisms, therefore explaining the wide range of responses to available therapy.

\section{Toxoplasma genotype and pathology}

Variation of clinical presentation and severity of disease in susceptible individuals has been attributed to several factors, including host genetic heterogeneity and parasite genotype (Boothroyd and Grigg 2002). We have typed T. gondii strains in Brazil (Vallochi et al 2005b) and our findings reveal that the highly clonal population structure of $T$. gondii seen in North America and Europe does not predominate in South America (Khan et al 2006). Identification of the direct players in host-pathogen interactions during the initial infection and chronic phases of the disease is perhaps the best hope for better clinical treatment in this region.

Population studies analyzing more than 50 different genetic markers have identified a limited number of $T$. gondii genotypes in nature, despite the presence of a sexual phase in the life cycle, a wide geographical distribution and a broad range of intermediate hosts. Phylogenetic analysis detects 2 main groups in $T$. gondii population. From a practical point of view, 3 main lineages (type I, type II, and type III) that despite sharing about 98\% genetic identity differ in virulence and epidemiological pattern of occurrence (Darde 2004; Switaj et al 2005), are usually considered. For most groups, allelic polymorphism is low (2 to 4 alleles) (Darde et al 1992; Howe and Sibley 1995; Ajzenberg et al 2002), indicating that they descend recently from two closely-related parents that underwent a small number of genetic recombination events. Less than $1 \%$ of the previously studied strains contain unique genotypes and high divergence of DNA sequence, and have therefore been considered 'exotic' or 'atypical' strains (Su et al 2003). However, it was demonstrated that sexual recombination combining polymorphisms in two of these distinct and competing clonal lines, can be a powerful force driving the natural evolution of virulence in this highly successful pathogen (Grigg et al 2001).

The apparently low genetic diversity in $T$. gondii may have been underestimated because most parasite strains in previous studies were collected from human patients and domestic animals in North America and Europe. The choice largely employed by researchers is using the $S A G 2$ locus for rapid typing since it is capable of distinguishing all three alleles from a single locus (Howe et al 1997). This method is also widely used in other genes where the population structure has not been studied so extensively, therefore genetic diversity is under-represented. Several studies have examined the distribution of genotypes in chickens from countries such as Egypt, Argentina, India, and Brazil (Dubey et al 2002, 2003a, 2003b, 2003c; Sreekumar et al 2003; Lehmann et al 2004), but the genetic studies were limited by the use of only one marker (SAG2) (except [Sreekumar et al 2003; Lehmann et al 2004]), and because chickens in farms are indicators of strain prevalence in a domestic or peridomestic environment. Strains isolated from humans and animals (rabbit, mouse, goat, chickens, and dogs) in Minas Gerais, Brazil were analyzed by polymerase chain reactionrestriction fragment length polymorphism (PCR-RFLP) at eight independent loci and all strains carried recombinant genotypes, with typical types I, II, or III in almost all loci assessed (de Melo Ferreira et al 2006).

We also have identified type I $T$. gondii strains by PCR-based typing at the $S A G 2$ locus in retinochoroidal specimens from Brazil (Vallochi et al 2005b). When analyzed by multilocus PCR-RFLP, our recent findings reveal that the highly clonal population structure of $T$. gondii seen in North America and Europe does not predominate in South America (Khan et al 2006). Consistent with this observation, T. gondii strains isolated from French Guiana patients are also highly diversified and not characteristic of a clonal organism as seen in North America strains (Ajzenberg et al 2004).

In the Brazilian strains, genotyping showed no cases of mixed infection (two alleles at a given locus). Unfortunately, the true extent of sequence divergence is not captured by multilocus RFLP and microsatellite analysis tends to overestimate genetic divergence. The UPRT-1 intron sequence was compared, and all except one strain from Brazil proved to have multiple additional polymorphisms not seen in the clonal lineages. This analysis suggested the presence of more than one predominant haplotype in Brazil along with less common unique genotypes (Khan et al 2006).

It has been suggested previously that such divergent strains are more ancient in origin than the recently derived clonal lineages and that $T$. gondii expansion is linked to enhanced oral transmission between intermediate hosts, a trait not shared by other closely related parasites ( $\mathrm{Su}$ et al 2003). Despite of high serologic prevalence and level of recurrent ocular disease in Erechim, Brazil (Glasner et al 1992), it is premature to say that sexual reproduction plays a central role in the population structure of $T$. gondii, since there were no cases of mixed infection. Given that the samples are from two small outbreaks and one of them due to food borne. It is likewise early to describe the epidemiology of 
toxoplasmosis in Brazil, since it is a country of continential size, boasting tropical and subtropical areas.

Recent studies in mice have identified some genes responsible for the strain-specific differences in virulence (Taylor et al 2006; Saeij et al 2007), where type I strains are more virulent than types II and III. As virulence is a multigenic trait, crossing the less virulent type II and type III strains generates some F1 progeny in which the virulence is greatly enhanced. The use of QTL mapping in such progeny identified a total of five virulence loci, including one on chromosome VIIa, which was found to correspond to ROP 18, and one on chromosome VIIb, which corresponded to a gene encoding another rhoptry kinase, ROP16 (Saeij et al 2007). ROP18 encodes the ROP18 protein, which is a functional serine kinase and is secreted into host cells (Taylor et al 2006). ROP16 is a key modulator of the host response and the three clonal lineages differ in their level of activation of the STAT signaling pathway. As this is the pathway to the crucial cytokine interleukin 12 , ROP16 is involved in this effect (Saeij et al 2007). It seems that these eukaryotic pathogens can secrete protein kinases into host cells to subvert host-cell signaling pathways and that this explains many of the differences in virulence among the three dominant clonal lineages.

Our findings reveal that the genetic makeup of $T$. gondii is more complex than previously recognized and are in agreement that unique or divergent genotypes may contribute to different clinical outcomes of toxoplasmosis in different localities. Further strain comparisons based on a wider set of sequence based markers will be necessary to define the global population structure of $T$. gondii and to resolve the relationships between major strain types seen in different geographic regions.

\section{Host genotype and the immune response to $T$. gondii}

A wide array of studies has further demonstrated differences in genotype and allele frequencies of cytokine gene polymorphisms depending on ethnicity and race (Golovleva et al 1997; Cox et al 2001; Uboldi de Capei et al 2003). Cytokines and chemokines and Toll-like receptors play a key role in the regulation of the type and magnitude of immune response, and the polymorphic nature of these genes may confer further flexibility to the immune response (Schroder and Schumann 2005). We have analyzed some of the genes involved in the response against $T$. gondii infection, whose functions are detailed in the following pages.

\section{Toll-like receptors}

Toll-like receptors (TLRs) have been recently defined as important transmembrane proteins that can confer a certain degree of specificity to the cells of the innate immune compartment. TLRs, also referred to as pattern recognition receptors (PRRs), have been implicated in recognition of every known category of pathogen that causes human disease and whose signaling through the common adaptor molecule myeloid differentiation primary-response protein 88 (MyD88) is essential in proinflammatory cytokine responses to many microbial pathogens.

TLRs can recognize traces of microbial components and orchestrate an early defense, largely dependent on the activation of nuclear factor-kappaB (NF- $\mathrm{B})$, which will lead to the production of proinflammatory cytokines and triggering of microbiostatic/microbicidal effector mechanisms (Iwasaki and Medzhitov 2004). While major advances have been made in the assignment of individual TLRs to defined roles in bacterial infections (Takeda et al 2003), such identification has only recently begun to emerge in protozoan parasites (Gazzinelli et al 2004).

Mice that are deficient in the TLR adaptor protein MyD88 were found to have a pronounced decrease in IL12 production by peritoneal macrophages, neutrophils, and splenic DC in response to soluble tachyzoite antigen (STAg) stimulation in vivo and in vitro being highly susceptible to the acute infection with low doses of the infective stage of T. gondii (Scanga et al 2002). At this lower parasite dose, neither TLR2 nor TLR4 were important for mouse resistance to infection with T. gondii. In addition, DC from TLR2- or TLR4-KO mice developed normal IL-12 responses to STAg (Scanga et al 2002) just as PMNs from TLR2-KO animals did (Del Rio et al 2004). TLR2-KO mice produce sufficient IL-12 to mediate partial protection that is nonetheless not enough to provide complete resistance to high dose infection, as compared to the wild type or TLR4-KO mice (Mun et al 2003). Hence, TLR2 might be involved in the early activation of the innate immune system during infection with T. gondii to be partially involved in the parasite recognition and MyD88 activation during early stages of infection with T. gondii. It seems that the defect seen in TLR2-KO mice is due to inefficient activation of microbicidal functions, with diminished nitric-oxide production by macrophages (Mun et al 2003).

Alternatively, MyD88-dependent neutrophil production of CCL2 (monocyte chemoattractant protein 1), but not IL-12, is dependent upon TLR2 signaling and defective CCL2 release could confer partial susceptibility to infection (Del Rio et al 
2004). Of note, neutrophil IL-12 production is not dependent upon parasite cyclophilin-18 (C-18), a T. gondii protein shown to trigger DC IL-12 through CCR5 ligation (Aliberti et al 2003). Thus, $T$. gondii possesses multiple molecules triggering distinct MyD88-dependent signaling cascades, and as these pathways are independently regulated, they may lead to distinct profiles of cytokine production (Del Rio et al 2004).

MyD88 signaling occurs also through IL-1R or IL-18R, but ICE-KO mice (lacking functional IL-1 and IL-18) exhibit no increased susceptibility to infection suggesting that signaling through IL-1R and IL-18R is not essential for responses against $T$. gondii infection. Importantly, TLR1-, TLR2-, TLR4-, TLR6-, and TLR9-KO mice exhibited similar resistance to infection compared with wild-type mice suggesting that these receptors are not independently essential for control of T. gondii infection (Hitziger et al 2005).

A recent study from our laboratory indicates that there is no association between polymorphisms in TLR2 (Arg677Trp and Arg763Gln) and TLR4 (Asp299Gly) and ocular toxoplasmosis in Brazilian patients (unpublished observations), a finding in keeping with the observations in the murine model.

On the other hand, of the whole family of TLRs, two distinct TLR have been implicated in the recognition of protein ligands. TLR5 has been shown to be triggered by bacterial flagellin while TLR11 signaling is stimulated by protease sensitive molecules in uropathogenic bacteria (Hayashi et al 2001; Zhang et al 2004). TLR11 was implicated in resistance to $T$. gondii when an additional ligand in the parasite, $T$. gondii profilin (PTG), that apparently triggers high DC IL-12 production by a MyD88 dependent but CCR5 independent pathway, was discovered (Yarovinsky et al 2005). Interestingly, while DC IL-12 production appeared to be almost totally impaired in TLR11-KO mice infected with T. gondii, these animals, unlike either MyD88 or IL-12-KO mice (Reis e Sousa et al 1997) retained partial resistance to challenge and survived the acute phase of the infection, most likely due to a residual IFN- $\gamma$ response (Yarovinsky et al 2005). It is important to note however, that human TLR 11 is nonfunctional because of the presence of a stop codon in the gene (Zhang et al 2004). At present it is not clear whether TLR11 recognition of $T$. gondii is of importance in limiting infection in other mammalian species or whether humans utilize alternative pattern recognition receptors in the innate response to $T$. gondii.

\section{Interleukin-12}

Immunity to $T$. gondii involves acute inflammatory responses and antigen-specific adaptive immunity (Denkers and Gazzi- nelli 1998; Cai et al 2000). Central to host resistance is the generation of IFN- $\gamma$ by innate-type natural killer (NK) cells and adaptive CD4 and CD8 T lymphocytes (Suzuki et al 1988, 1989b). IL-12 has been identified as critical for driving prompt IFN- $\gamma$ production and proper differentiation of Th1 lymphocytes during the immune response to $T$. gondii (Gazzinelli et al 1994b; Yap et al 2000).

IL-12 is produced by PMNs, DC, B cells and other antigen-presenting cells (APCs). PMNs store cytokines in pre-formed pools namely IL-12, IL-6, MIP-2 in mouse neutrophils in the absence of infection (Terebuh et al 1992; Bliss et al 2000; Matzer et al 2001), and IL-4 in PMN from healthy human donors (Brandt et al 2000). T. gondii induces secretion of IL-12 directly and rapidly by both human and mouse neutrophils, DCs as well as MØ (Gazzinelli et al 1993; Reis e Sousa et al 1997; Bliss et al 1999a, 1999b; Denkers et al 2003; Robben et al 2004). Release of IL-12 does not require IFN- $\gamma$ priming since responses are intact in gene-targeted mice lacking this cytokine. On the other hand, recombinant TNF- $\alpha$ alone stimulates CCL 2 and CCL4 production by $\mathrm{PMN}$, and therefore, the ability of $T$. gondii to trigger TNF- $\alpha$ may provide an important positive feedback loop for release of neutrophil CCL2 and CCL4, important chemokines which recruit macrophages and other cells to infected tissue. T. gondii also induces up regulation of RANTES (CCL5), MIP-3 $\alpha$ (CCL20) and macrophage chemoattractant protein-1 (MCP-1; CCL2) gene transcription by PMN (Bennouna et al 2003), which recruited to the site of infection by chemokines such as IL- 8 and MCP-1, are themselves equipped to immediately release cytokines and chemokines that contribute further to cell recruitment and activation.

IL-12 is composed of two subunits, IL-12 p40 and IL-12 p35. In the absence of the IL-12 p40 gene or the IL-12-receptor-associated signal transducers Tyk2 and STAT-4, IFN- $\gamma$ production is severely impaired resulting in enhanced susceptibility to acute T. gondii infection (Yap and Sher 1999; Cai et al 2000; Shaw et al 2003). In contrast, the IL-12-related cytokine, IL-23, which is composed of the shared IL-12 p40 subunit and a unique p19 subunit is not required or essential for mouse immunity to $T$. gondii infection (Lieberman et al 2004). Thus, IL-12 p40 production by DC and via a MyD88-dependent recognition mechanism is critical and perhaps sufficient for initiating IFN- $\gamma$-mediated immunity to T. gondii (Reis e Sousa et al 1997; Scanga et al 2002). Related cytokines such as IL-18 and IL-23 may instead play a pathogenic role (Mordue et al 2001; Gaddi and Yap 2007). 
Studies of differential production of IL-12 in BALB/c and DBA/2 mice suggest that strain-specific variation not encoded by MHC genes affects IL-12 production with a skewing of antigen-specific recall responses to either a Th1 or a Th2 direction (Gieni et al 1996). In humans, deletions of IL-12 p40 or IL-12 receptors lead to serious impairment of immunity against intracellular bacteria (Altare et al 1998; de Jong et al 1998). A complete genomic sequence analysis of the $I L-12$ gene encoding its p40 subunit $(I L-12 B)$ identified several intronic polymorphisms, a single-nucleotide polymorphism $(\mathrm{SNP})$ at position $+16974(+16974 \mathrm{~A} / \mathrm{C})$ in the 3'-untranslated region (UTR) of $I L-12 B$ (Hall et al 2000; Huang et al 2000) and a promoter polymorphism (IL-12Bpro) (Morahan et al 2002).

Association between genotype $(+16974 \mathrm{~A} / \mathrm{C})$ and IL-12p40 production by stimulated PBMC was observed and depend on the stimuli used. There is a significantly decreased IL-12 p40 secretion for the following order of genotypes: $\mathrm{AA}>\mathrm{CA}>\mathrm{CC}$, after stimulation of $\mathrm{PBMC}$ with $\mathrm{C} 3$-binding glycoprotein (C3bgp) in contrast to lipopolysaccharide, phytohaemagglutinin and pokeweed mitogen (Stanilova and Miteva 2005). Furthermore, polymorphisms in the IL12B 3'UTR gene have been show to influence the secretion of IL-12 and susceptibility to Type 1 diabetes (Windsor et al 2004), and the promoter polymorphism may influence the outcome of malaria infection in at least one African population (Morahan et al 2002).

\section{CCR5}

Although low-level IFN- $\gamma$ production occurs in the absence of IL-12 signaling, optimal induction is strictly IL-12dependent (Cai et al 2000). Therefore, much effort has been dedicated to disclose the mechanism(s) by which $T$. gondii tachyzoites elicit the production of IL-12 during the initial stages of infection.

The best defined mechanism by which $T$. gondii induces the production of IL-12 is through the parasite-derived cyclophilin-18, which signals murine DCs to produce IL12 via the chemokine receptor CCR5 (Aliberti et al 2000; Aliberti et al 2003). The biological relevance of the unusual requirement for a chemokine receptor to participate in microbial recognition by DCs is supported by the observation that IL-12 production is decreased during acute infections of CCR5-KO animals (Aliberti et al 2000), although defects in cell migration could also contribute to this susceptible phenotype. In theory, cell-surface CCR5 on DCs could deliver signals derived from stimulation with autologous chemokines that have been induced following microbial stimulation or could be directly triggered by pathogen derived ligands.

In humans, a mutant allele of the CCR5 gene, bearing a 32-bp deletion, results in reduced CCR5 cell surface expression (Blanpain et al 2000). However, we couldn't observe association between the allele CCR $5 \Delta 32$ and ocular toxoplasmosis in Brazilian patients (unpublished observations). Incidentally, we and others have found this variant to be quite rare in Brazilian population samples (unpublished results).

The IL-12 levels observed after stimulation of murine DCs with C-18 are much lower than those seen after stimulation with whole-parasite lysate or with a pool of tachyzoitesecreted proteins, indicating that pathways other than those initiated by CCR 5 and C-18 might also be important for IL-12 production by DCs (Aliberti et al 2003).

\section{Conclusion}

While the data summarized in this review demonstrate that the binomial IL-12 and IFN- $\gamma$ production is critical to resistance to T. gondii infection in mice, and that an intricate mechanism involving simultaneous activation of different signaling pathways could be required for induction and control of IL-12 during acute infection with $T$. gondii, much remains to be learned about the mechanisms involved and their relevance to parasite and host interactions during natural infection in humans. We had discussed the importance of the genetic background of both the parasite and the host in the establishment of ocular disease and the major questions concerning the specific receptors and parasite ligands required for innate immunity response triggering and how these interactions result in resistance to $T$. gondii.

\section{Acknowledgments}

Supported by Fundação de Amparo a Pesquisa do Estado de São Paulo (FAPESP), Conselho Nacional de Desenvolvimento Científico e Tecnológico (CNPq), and the Pan-American Association of Ophthalmology (PAAO).

\section{References}

Ajzenberg D, Banuls AL, Su C, et al. 2004. Genetic diversity, clonality and sexuality in Toxoplasma gondii. Int J Parasitol, 34:1185-96.

Ajzenberg D, Cogne N, Paris L, et al. 2002. Genotype of 86 Toxoplasma gondii isolates associated with human congenital toxoplasmosis, and correlation with clinical findings. J Infect Dis, 186:684-9.

Aliberti J, Reis e Sousa C, Schito M, et al. 2000. CCR5 provides a signal for microbial induced production of IL-12 by CD8 alpha+ dendritic cells. Nat Immunol, 1:83-7.

Aliberti J, Valenzuela JG, Carruthers VB, et al. 2003. Molecular mimicry of a CCR5 binding-domain in the microbial activation of dendritic cells. Nat Immunol, 4:485-90. 
Altare F, Durandy A, Lammas D, et al. 1998. Impairment of mycobacterial immunity in human interleukin-12 receptor deficiency. Science, 280:1432-5.

Beaman MH, Wong SY and Remington JS. 1992. Cytokines, Toxoplasma and intracellular parasitism. Immunol Rev, 127:97-117.

Bennouna S, Bliss SK, Curiel TJ, et al. 2003. Cross-talk in the innate immune system: neutrophils instruct recruitment and activation of dendritic cells during microbial infection. J Immunol, 171:6052-8.

Black CM, Israelski DM, Suzuki Y, et al. 1989. Effect of recombinant tumour necrosis factor on acute infection in mice with Toxoplasma gondii or Trypanosoma cruzi. Immunology, 68:570-4.

Blanpain C, Lee B, Tackoen M, et al. 2000. Multiple nonfunctional alleles of CCR5 are frequent in various human populations. Blood, 96:1638-45.

Bliss SK, Butcher BA, Denkers EY. 2000. Rapid recruitment of neutrophils containing prestored IL-12 during microbial infection. J Immunol, 165:4515-21.

Bliss SK, Marshall AJ, Zhang Y, et al. 1999a. Human polymorphonuclear leukocytes produce IL-12, TNF-alpha, and the chemokines macrophageinflammatory protein-1 alpha and -1 beta in response to Toxoplasma gondii antigens. J Immunol, 162:7369-75.

Bliss SK, Zhang Y, Denkers EY. 1999b. Murine neutrophil stimulation by Toxoplasma gondii antigen drives high level production of IFN-gammaindependent IL-12. J Immunol, 163:2081-8.

Boothroyd JC, Grigg ME. 2002. Population biology of Toxoplasma gondii and its relevance to human infection: do different strains cause different disease? Curr Opin Microbiol, 5:438-42.

Bosch-Driessen LE, Berendschot TT, Ongkosuwito JV, et al. 2002. Ocular toxoplasmosis: clinical features and prognosis of 154 patients. Ophthalmology, 109:869-78.

Bossi P, Bricaire F. 2004. Severe acute disseminated toxoplasmosis. Lancet, 364:579.

Brandt E, Woerly G, Younes AB, et al. 2000. IL-4 production by human polymorphonuclear neutrophils. J Leukoc Biol, 68:125-30.

Brezin AP, Cisneros B. 1999. Congenital and acquired infection in ocular toxoplasmosis [ARVO abstract]. Invest Ophthalmol Vis Sci, 40:S383.

Brown CR, McLeod R. 1990. Class I MHC genes and CD8+ T cells determine cyst number in Toxoplasma gondii infection. J Immunol, 145:3438-41.

Buzoni-Gatel D, Lepage AC, Dimier-Poisson IH, et al. 1997. Adoptive transfer of gut intraepithelial lymphocytes protects against murine infection with Toxoplasma gondii. J Immunol, 158:5883-9.

Cai G, Radzanowski T, Villegas EN, et al. 2000. Identification of STAT4dependent and independent mechanisms of resistance to Toxoplasma gondii. J Immunol, 165:2619-27.

Casciotti L, Ely KH, Williams ME, et al. 2002. CD8(+)-T-cell immunity against Toxoplasma gondii can be induced but not maintained in mice lacking conventional CD4(+) T cells. Infect Immun, 70:434-43.

Chang HR, Grau GE, Pechere JC. 1990. Role of TNF and IL-1 in infections with Toxoplasma gondii. Immunology, 69:33-7.

Collazo CM, Yap GS, Sempowski GD, et al. 2001. Inactivation of LRG47 and IRG-47 reveals a family of interferon gamma-inducible genes with essential, pathogen-specific roles in resistance to infection. $J$ Exp Med, 194:181-8.

Couvreur J, Thulliez P. 1996. [Acquired toxoplasmosis of ocular or neurologic site: 49 cases]. Presse Med, 25:438-42.

Cox ED, Hoffmann SC, DiMercurio BS, et al. 2001. Cytokine polymorphic analyses indicate ethnic differences in the allelic distribution of interleukin-2 and interleukin-6. Transplantation, 72:720-6.

Darde ML. 2004. Genetic analysis of the diversity in Toxoplasma gondii. Ann Ist Super Sanita, 40:57-63.

Darde ML, Bouteille B, Pestre-Alexandre M. 1992. Isoenzyme analysis of 35 Toxoplasma gondii isolates and the biological and epidemiological implications. J Parasitol, 78:786-94.

de Jong R, Altare F, Haagen IA, et al. 1998. Severe mycobacterial and Salmonella infections in interleukin-12 receptor-deficient patients. Science, 280:1435-8. de Melo Ferreira A, Vitor RW, Gazzinelli RT, et al. 2006. Genetic analysis of natural recombinant Brazilian Toxoplasmagondii strains by multilocus PCR-RFLP. Infect Genet Evol, 6:22-31.

Deckert-Schluter M, Schluter D, Schmidt D, et al. 1994. Toxoplasma encephalitis in congenic B10 and BALB mice: impact of genetic factors on the immune response. Infect Immun, 62:221-8.

Del Rio L, Butcher BA, Bennouna S, et al. 2004. Toxoplasma gondii triggers myeloid differentiation factor 88-dependent IL-12 and chemokine ligand 2 (monocyte chemoattractant protein 1) responses using distinct parasite molecules and host receptors. J Immunol, 172:6954-60.

Denkers EY, Butcher BA, Del Rio L, et al. 2004. Manipulation of mitogenactivated protein kinase/nuclear factor-kappaB-signaling cascades during intracellular Toxoplasma gondii infection. Immunol Rev, 201:191-205.

Denkers EY, Del Rio L, Bennouna S. 2003. Neutrophil production of IL-12 and other cytokines during microbial infection. Chem Immunol Allergy, 83:95-114.

Denkers EY, Gazzinelli RT. 1998. Regulation and function of T-cell-mediated immunity during Toxoplasma gondii infection. Clin Microbiol Rev, 11:569-88.

Dubey JP, Beattie CP. 1988. Toxoplasmosis of animals and man. Boca Raton, FL: CRC Press.

Dubey JP, Graham DH, Blackston CR, et al. 2002. Biological and genetic characterisation of Toxoplasma gondii isolates from chickens (Gallus domesticus) from Sao Paulo, Brazil: unexpected findings. Int $J$ Parasitol, 32:99-105.

Dubey JP, Graham DH, da Silva DS, et al. 2003a. Toxoplasma gondii isolates of free-ranging chickens from Rio de Janeiro, Brazil: mouse mortality, genotype, and oocyst shedding by cats. J Parasitol, 89:851-3.

Dubey JP, Graham DH, Dahl E, et al. 2003b. Isolation and molecular characterization of Toxoplasma gondii from chickens and ducks from Egypt. Vet Parasitol, 114:89-95.

Dubey JP, Venturini MC, Venturini L, et al. 2003c. Isolation and genotyping of Toxoplasma gondii from free-ranging chickens from Argentina. $J$ Parasitol, 89:1063-4.

Fatoohi F, Cozon GJ, Wallon M, et al. 2006. Systemic T cell response to Toxoplasma gondii antigen in patients with ocular toxoplasmosis. Jpn J Ophthalmol, 50:103-10.

Frenkel JK. 1988. Pathophysiology of toxoplasmosis. Parasitol Today, 4:273-8.

Frenkel JK. 1990. Toxoplasmosis in human beings. J Am Vet Med Assoc, 196:240-8.

Fujigaki S, Saito K, Takemura M, et al. 2002. L-tryptophan-Lkynurenine pathway metabolism accelerated by Toxoplasma gondii infection is abolished in gamma interferon-gene-deficient mice: cross-regulation between inducible nitric oxide synthase and indoleamine-2,3-dioxygenase. Infect Immun, 70:779-86.

Furtado GC, Cao Y, Joiner KA. 1992. Laminin on Toxoplasma gondii mediates parasite binding to the beta 1 integrin receptor alpha 6 beta 1 on human foreskin fibroblasts and Chinese hamster ovary cells. Infect Immun, 60:4925-31.

Gaddi PJ and Yap GS. 2007. Cytokine regulation of immunopathology in toxoplasmosis. Immunol Cell Biol, 85:155-9.

Gazzinelli R, Xu Y, Hieny S, et al. 1992. Simultaneous depletion of CD4+ and CD8+ T lymphocytes is required to reactivate chronic infection with Toxoplasma gondii. J Immunol, 149:175-80.

Gazzinelli RT, Brezin A, Li Q, et al. 1994a. Toxoplasma gondii: acquired ocular toxoplasmosis in the murine model, protective role of TNF-alpha and IFN-gamma. Exp Parasitol, 78:217-29.

Gazzinelli RT, Hakim FT, Hieny S, et al. 1991. Synergistic role of CD4+ and CD8+ T lymphocytes in IFN-gamma production and protective immunity induced by an attenuated Toxoplasma gondii vaccine. J Immunol, 146:286-92.

Gazzinelli RT, Hieny S, Wynn TA, et al. 1993. Interleukin 12 is required for the T-lymphocyte-independent induction of interferon gamma by an intracellular parasite and induces resistance in T-cell-deficient hosts. Proc Natl Acad Sci U S A, 90:6115-19. 
Gazzinelli RT, Ropert C, Campos MA. 2004. Role of the Toll/interleukin-1 receptor signaling pathway in host resistance and pathogenesis during infection with protozoan parasites. Immunol Rev, 201:9-25.

Gazzinelli RT, Wysocka M, Hayashi S, et al. 1994b. Parasite-induced IL12 stimulates early IFN-gamma synthesis and resistance during acute infection with Toxoplasma gondii. J Immunol, 153:2533-43.

Gazzinelli RT, Wysocka M, Hieny S, et al. 1996. In the absence of endogenous IL-10, mice acutely infected with Toxoplasma gondii succumb to a lethal immune response dependent on CD4+ T cells and accompanied by overproduction of IL-12, IFN-gamma and TNF-alpha. J Immunol, 157:798-805.

Gieni RS, Fang Y, Trinchieri G, et al. 1996. Differential production of IL-12 in BALB/c and DBA/2 mice controls IL-4 versus IFN-gamma synthesis in primed CD4 lymphocytes. Int Immunol, 8:1511-20.

Glasner PD, Silveira C, Kruszon-Moran D, et al. 1992. An unusually high prevalence of ocular toxoplasmosis in southern Brazil. Am J Ophthalmol, 114:136-44.

Golovleva I, Saha N, Beckman L. 1997. Ethnic differences in interferonalpha allele frequencies. Hum Hered, 47:185-8.

Grau GE, Tacchini-Cooler F, Piguet PF. 1992. Is TNF beneficial or deleterious in toxoplasmic encephalitis? Parasitol Today, 8:322-4; discussion 35-6.

Grigg ME, Bonnefoy S, Hehl AB, et al. 2001. Success and virulence in Toxoplasma as the result of sexual recombination between two distinct ancestries. Science, 294:161-5.

Hall MA, McGlinn E, Coakley G, et al. 2000. Genetic polymorphism of IL-12 p40 gene in immune-mediated disease. Genes Immun, 1:219-24.

Hayashi F, Smith KD, Ozinsky A, et al. 2001. The innate immune response to bacterial flagellin is mediated by Toll-like receptor 5. Nature, 410:1099-103.

Hill D, Dubey JP. 2002. Toxoplasma gondii: transmission, diagnosis and prevention. Clin Microbiol Infect, 8:634-40.

Hitziger N, Dellacasa I, Albiger B, et al. 2005. Dissemination of Toxoplasma gondii to immunoprivileged organs and role of Toll/interleukin-1 receptor signalling for host resistance assessed by in vivo bioluminescence imaging. Cell Microbiol, 7:837-48.

Holland GN. 2003. Ocular toxoplasmosis: a global reassessment. Part I: epidemiology and course of disease. Am J Ophthalmol, 136:973-88.

Holland GN. 2004. Ocular toxoplasmosis: a global reassessment. Part II: disease manifestations and management. Am J Ophthalmol, 137:1-17.

Howe DK, Honore S, Derouin F, et al. 1997. Determination of genotypes of Toxoplasma gondii strains isolated from patients with toxoplasmosis. J Clin Microbiol, 35:1411-14.

Howe DK and Sibley LD. 1995. Toxoplasma gondii comprises three clonal lineages: correlation of parasite genotype with human disease. J Infect Dis, 172:1561-6.

Hu MS, Schwartzman JD, Yeaman GR, et al. 1999. Fas-FasL interaction involved in pathogenesis of ocular toxoplasmosis in mice. Infect Immun, 67:928-35.

Hu S, Schwartzman JD, Kasper LH. 2001. Apoptosis within mouse eye induced by Toxoplasma gondii. Chin Med J (Engl), 114:640-4.

Huang D, Cancilla MR, Morahan G. 2000. Complete primary structure, chromosomal localisation, and definition of polymorphisms of the gene encoding the human interleukin-12 p40 subunit. Genes Immun, $1: 515-20$.

Iwasaki A, Medzhitov R. 2004. Toll-like receptor control of the adaptive immune responses. Nat Immunol, 5:987-95.

Jacquet A, Coulon L, De Neve J, et al. 2001. The surface antigen SAG3 mediates the attachment of Toxoplasma gondii to cell-surface proteoglycans. Mol Biochem Parasitol, 116:35-44.

Johnson AM. 1984. Strain-dependent, route of challenge-dependent, murine susceptibility to toxoplasmosis. Z Parasitenkd, 70:303-9.

Johnson J, Suzuki Y, Mack D, et al. 2002. Genetic analysis of influences on survival following Toxoplasma gondii infection. Int J Parasitol, 32:179-85.

Johnson LL. 1992. A protective role for endogenous tumor necrosis factor in Toxoplasma gondii infection. Infect Immun, 60:1979-83.
Kasper LH, Khan IA, Ely KH, et al. 1992. Antigen-specific (p30) mouse CD8+ $\mathrm{T}$ cells are cytotoxic against Toxoplasma gondii-infected peritoneal macrophages. J Immunol, 148:1493-8.

Khan A, Jordan C, Muccioli C, et al. 2006. Genetic divergence of Toxoplasma gondii strains associated with ocular toxoplasmosis, Brazil. Emerg Infect Dis, 12:942-9.

Khan IA, Schwartzman JD, Matsuura T, et al. 1997. A dichotomous role for nitric oxide during acute Toxoplasma gondii infection in mice. Proc Natl Acad Sci U S A, 94:13955-60.

Lambert H, Hitziger N, Dellacasa I, et al. 2006. Induction of dendritic cell migration upon Toxoplasma gondii infection potentiates parasite dissemination. Cell Microbiol, 8:1611-23.

Langermans JA, Van der Hulst ME, Nibbering PH, et al. 1992. IFN-gammainduced L-arginine-dependent toxoplasmastatic activity in murine peritoneal macrophages is mediated by endogenous tumor necrosis factor-alpha. J Immunol, 148:568-74.

Lehmann T, Graham DH, Dahl ER, et al. 2004. Variation in the structure of Toxoplasma gondii and the roles of selfing, drift, and epistatic selection in maintaining linkage disequilibria. Infect Genet Evol, 4:07-14.

Lieberman LA, Cardillo F, Owyang AM, et al. 2004. IL-23 provides a limited mechanism of resistance to acute toxoplasmosis in the absence of IL-12. J Immunol, 173:1887-93.

Liesenfeld O. 1999. Immune responses to Toxoplasma gondii in the gut. Immunobiology, 201:229-39.

Liesenfeld O, Kosek J, Remington JS, et al. 1996. Association of CD4+ $\mathrm{T}$ cell-dependent, interferon-gamma-mediated necrosis of the small intestine with genetic susceptibility of mice to peroral infection with Toxoplasma gondii. J Exp Med, 184:597-607.

Lu F, Huang S, Hu MS, et al. 2005. Experimental ocular toxoplasmosis in genetically susceptible and resistant mice. Infect Immun, 73:5160-5

Lu F, Huang S, Kasper LH. 2004. CD4+ T cells in the pathogenesis of murine ocular toxoplasmosis. Infect Immun, 72:4966-72.

Lyons RE, Anthony JP, Ferguson DJ, et al. 2001. Immunological studies of chronic ocular toxoplasmosis: up-regulation of major histocompatibility complex class I and transforming growth factor beta and a protective role for interleukin-6. Infect Immun, 69:2589-95.

Mackay CR. 2001. Chemokines: immunology's high impact factors. Nat Immunol, 2:95-101.

MacKenzie CR, Gonzalez RG, Kniep E, et al. 1999. Cytokine mediated regulation of interferon-gamma-induced IDO activation. Adv Exp Med Biol, 467:533-9.

Manger ID, Hehl AB, Boothroyd JC. 1998. The surface of Toxoplasma tachyzoites is dominated by a family of glycosylphosphatidylinositolanchored antigens related to SAG1. Infect Immun, 66:2237-44.

Marshall AJ, Brunet LR, van Gessel Y, et al. 1999. Toxoplasma gondii and Schistosoma mansoni synergize to promote hepatocyte dysfunction associated with high levels of plasma TNF-alpha and early death in C57BL/6 mice. J Immunol, 163:2089-97.

Matzer SP, Baumann T, Lukacs NW, et al. 2001. Constitutive expression of macrophage-inflammatory protein 2 (MIP-2) mRNA in bone marrow gives rise to peripheral neutrophils with preformed MIP-2 protein. J Immunol, 167:4635-43.

McLeod R, Eisenhauer P, Mack D, et al. 1989a. Immune responses associated with early survival after peroral infection with Toxoplasma gondii. J Immunol, 142:3247-55.

McLeod R, Skamene E, Brown CR, et al. 1989b. Genetic regulation of early survival and cyst number after peroral Toxoplasma gondii infection of $\mathrm{A} \times \mathrm{B} / \mathrm{B} \times \mathrm{A}$ recombinant inbred and $\mathrm{B} 10$ congenic mice. J Immunol, 143:3031-4.

Mele A, Paterson PJ, Prentice HG, et al. 2002. Toxoplasmosis in bone marrow transplantation: a report of two cases and systematic review of the literature. Bone Marrow Transplant, 29:691-8.

Montoya JG, Liesenfeld O. 2004. Toxoplasmosis. Lancet, 363:1965-76.

Montoya JG, Remington JS. 1996. Toxoplasmic chorioretinitis in the setting of acute acquired toxoplasmosis. Clin Infect Dis, 23:277-82. 
Morahan G, Boutlis CS, Huang D, et al. 2002. A promoter polymorphism in the gene encoding interleukin-12 p40 (IL12B) is associated with mortality from cerebral malaria and with reduced nitric oxide production. Genes Immun, 3:414-18.

Mordue DG, Monroy F, La Regina M, et al. 2001. Acute toxoplasmosis leads to lethal overproduction of Th1 cytokines. J Immunol, 167:4574-84.

Mun HS, Aosai F, Norose K, et al. 2003. TLR2 as an essential molecule for protective immunity against Toxoplasma gondii infection. Int Immunol, 15:1081-7.

Norose K, Mun HS, Aosai F, et al. 2003. IFN-gamma-regulated Toxoplasma gondii distribution and load in the murine eye. Invest Ophthalmol Vis Sci, 44:4375-81.

Nussenblatt RB, Belfort R, Jr. 1994. Ocular toxoplasmosis. An old disease revisited. JAMA, 271:304-7.

Ortega-Barria E, Boothroyd JC. 1999. A Toxoplasma lectin-like activity specific for sulfated polysaccharides is involved in host cell infection. J Biol Chem, 274:1267-76.

Parker SJ, Roberts CW, Alexander J. 1991. CD8+ T cells are the major lymphocyte subpopulation involved in the protective immune response to Toxoplasma gondii in mice. Clin Exp Immunol, 84:207-12.

Perez de Lema G, Maier H, Nieto E, et al. 2001. Chemokine expression precedes inflammatory cell infiltration and chemokine receptor and cytokine expression during the initiation of murine lupus nephritis. $J$ Am Soc Nephrol, 12:1369-82.

Petersen E, Dubey JP. 2001. Biology of toxoplasmosis. In: Joynson DHM, Wreghitt TG (Eds). Toxoplasmosis: a comprehensive clinical guide. Cambridge, UK: Cambridge University Press, pp. 1-42.

Reis e Sousa C, Hieny S, Scharton-Kersten T, et al. 1997. In vivo microbial stimulation induces rapid CD40 ligand-independent production of interleukin 12 by dendritic cells and their redistribution to $T$ cell areas. J Exp Med, 186:1819-29.

Robben PM, Mordue DG, Truscott SM, et al. 2004. Production of IL-12 by macrophages infected with Toxoplasma gondii depends on the parasite genotype. J Immunol, 172:3686-94.

Roberts CW, Cruickshank SM, Alexander J. 1995. Sex-determined resistance to Toxoplasma gondii is associated with temporal differences in cytokine production. Infect Immun, 63:2549-55.

Roberts F, Roberts CW, Ferguson DJ, et al. 2000. Inhibition of nitric oxide production exacerbates chronic ocular toxoplasmosis. Parasite Immunol, 22:1-5.

Saeij JP, Coller S, Boyle JP, et al. 2007. Toxoplasma co-opts host gene expression by injection of a polymorphic kinase homologue. Nature, 445:324-7.

Scanga CA, Aliberti J, Jankovic D, et al. 2002. Cutting edge: MyD88 is required for resistance to Toxoplasma gondii infection and regulates parasite-induced IL-12 production by dendritic cells. J Immunol, 168:5997-6001.

Scharton-Kersten TM, Wynn TA, Denkers EY, et al. 1996. In the absence of endogenous IFN-gamma, mice develop unimpaired IL-12 responses to Toxoplasma gondii while failing to control acute infection. J Immunol, 157:4045-54.

Scharton-Kersten TM, Yap G, Magram J, et al. 1997. Inducible nitric oxide is essential for host control of persistent but not acute infection with the intracellular pathogen Toxoplasma gondii. J Exp Med, 185:1261-73.

Schroder NW, Schumann RR. 2005. Single nucleotide polymorphisms of Toll-like receptors and susceptibility to infectious disease. Lancet Infect Dis, 5:156-64.

Shaw MH, Boyartchuk V, Wong S, et al. 2003. A natural mutation in the Tyk2 pseudokinase domain underlies altered susceptibility of B10. $\mathrm{Q} / \mathrm{J}$ mice to infection and autoimmunity. Proc Natl Acad Sci U S A, 100:11594-9.

Shen DF, Matteson DM, Tuaillon N, et al. 2001. Involvement of apoptosis and interferon-gamma in murine toxoplasmosis. Invest Ophthalmol Vis Sci, 42:2031-6.

Sibley LD, Adams LB, Krahenbuhl JL. 1993. Macrophage interactions in toxoplasmosis. Res Immunol, 144:38-40.
Silva NM, Rodrigues CV, Santoro MM, et al. 2002. Expression of indoleamine 2,3-dioxygenase, tryptophan degradation, and kynurenine formation during in vivo infection with Toxoplasma gondii: induction by endogenous gamma interferon and requirement of interferon regulatory factor 1. Infect Immun, 70:859-68.

Silveira C. 2002. [Toxoplasmose: Dúvidas e controvérsias.] Erechim, RS: EdiFAPES.

Silveira C, Belfort R Jr., Burnier M Jr., et al. 1988. Acquired toxoplasmic infection as the cause of toxoplasmic retinochoroiditis in families. $\mathrm{Am}$ J Ophthalmol, 106:362-4.

Silveira C, Belfort R Jr, Muccioli C, et al. 2001. A follow-up study of Toxoplasma gondii infection in southern Brazil. Am J Ophthalmol, 131:351-4.

Sreekumar C, Graham DH, Dahl E, et al. 2003. Genotyping of Toxoplasma gondii isolates from chickens from India. Vet Parasitol, 118:187-94.

Stanford MR, See SE, Jones LV, et al. 2003. Antibiotics for toxoplasmic retinochoroiditis: an evidence-based systematic review. Ophthalmology, 110:926-31; quiz 31-2.

Stanilova S, Miteva L. 2005. Taq-I polymorphism in 3'UTR of the IL-12B and association with IL-12p40 production from human PBMC. Genes Immun, 6:364-6.

Su C, Evans D, Cole RH, et al. 2003. Recent expansion of Toxoplasma through enhanced oral transmission. Science, 299:414-16.

Su C, Howe DK, Dubey JP, et al. 2002. Identification of quantitative trait loci controlling acute virulence in Toxoplasma gondii. Proc Natl Acad Sci U S A, 99:10753-8.

Suzuki Y. 2002. Immunopathogenesis of cerebral toxoplasmosis. $J$ Infect Dis, 186(Suppl 2):S234-40.

Suzuki Y, Conley FK, Remington JS. 1989a. Differences in virulence and development of encephalitis during chronic infection vary with the strain of Toxoplasma gondii. J Infect Dis, 159:790-4.

Suzuki Y, Conley FK, Remington JS. 1989b. Importance of endogenous IFN-gamma for prevention of toxoplasmic encephalitis in mice. J Immunol, 143:2045-50.

Suzuki Y, Orellana MA, Schreiber RD, et al. 1988. Interferon-gamma: the major mediator of resistance against Toxoplasma gondii. Science, 240:516-18

Suzuki Y, Orellana MA, Wong SY, et al. 1993. Susceptibility to chronic infection with Toxoplasma gondii does not correlate with susceptibility to acute infection in mice. Infect Immun, 61:2284-8.

Suzuki Y, Wong SY, Grumet FC, et al. 1996. Evidence for genetic regulation of susceptibility to toxoplasmic encephalitis in AIDS patients. J Infect Dis, 173:265-8.

Switaj K, Master A, Skrzypczak M, et al. 2005. Recent trends in molecular diagnostics for Toxoplasma gondii infections. Clin Microbiol Infect, 11:170-6.

Takeda K, Kaisho T, Akira S. 2003. Toll-like receptors. Annu Rev Immunol, 21:335-76.

Taylor GA, Collazo CM, Yap GS, et al. 2000. Pathogen-specific loss of host resistance in mice lacking the IFN-gamma-inducible gene IGTP. Proc Natl Acad Sci U S A, 97:751-5.

Taylor S, Barragan A, Su C, et al. 2006. A secreted serine-threonine kinase determines virulence in the eukaryotic pathogen Toxoplasma gondii. Science, 314:1776-80.

Tenter AM, Heckeroth AR, Weiss LM. 2000. Toxoplasma gondii: from animals to humans. Int J Parasitol, 30:1217-58.

Terebuh PD, Otterness IG, Strieter RM, et al. 1992. Biologic and immunohistochemical analysis of interleukin-6 expression in vivo. Constitutive and induced expression in murine polymorphonuclear and mononuclear phagocytes. Am J Pathol, 140:649-57.

Uboldi de Capei MU, Dametto E, Fasano ME, et al. 2003. Genotyping for cytokine polymorphisms: allele frequencies in the Italian population. Eur J Immunogenet, 30:5-10.

Vallochi AL, da Silva Rios L, Nakamura MV, et al. 2005a. The involvement of autoimmunity against retinal antigens in determining disease severity in toxoplasmosis. $J$ Autoimmun, 24:25-32. 
Vallochi AL, Muccioli C, Martins MC, et al. 2005b. The genotype of Toxoplasma gondii strains causing ocular toxoplasmosis in humans in Brazil. Am J Ophthalmol, 139:350-1.

Vallochi AL, Nakamura MV, Schlesinger D, et al. 2002. Ocular toxoplasmosis: more than just what meets the eye. Scand J Immunol, 55:324-8.

Vallochi AL, Yamamoto JH, Schlesinger D, et al. 2001. Lack of evidence for superantigen activity of Toxoplasma gondii towards human $\mathrm{T}$ cells. Braz J Med Biol Res, 34:1023-31.

Williams DM, Grumet FC, Remington JS. 1978. Genetic control of murine resistance to Toxoplasma gondii. Infect Immun, 19:416-20.

Windsor L, Morahan G, Huang D, et al. 2004. Alleles of the IL12B 3'UTR associate with late onset of type 1 diabetes. Hum Immunol, 65:1432-6.

Wong SY, Remington JS. 1993. Biology of Toxoplasma gondii. AIDS, 7:299-316.
Yamamoto JH, Vallochi AL, Silveira C, et al. 2000. Discrimination between patients with acquired toxoplasmosis and congenital toxoplasmosis on the basis of the immune response to parasite antigens. J Infect Dis, 181:2018-22.

Yap G, Pesin M, Sher A. 2000. Cutting edge: IL-12 is required for the maintenance of IFN-gamma production in T cells mediating chronic resistance to the intracellular pathogen, Toxoplasma gondii. J Immunol, 165:628-31.

Yap GS, Sher A. 1999. Cell-mediated immunity to Toxoplasma gondii: initiation, regulation and effector function. Immunobiology, 201:240-7.

Yarovinsky F, Zhang D, Andersen JF, et al. 2005. TLR11 activation of dendritic cells by a protozoan profilin-like protein. Science, 308:1626-9.

Zhang D, Zhang G, Hayden MS, et al. 2004. A toll-like receptor that prevents infection by uropathogenic bacteria. Science, 303:1522-6. 